\title{
Changes in the species and functional trait composition of the seed bank during semi-natural grassland assembly: seed bank disassembly or ecological palimpsest?
}

\author{
Kenny Helsen, Martin Hermy \& Olivier Honnay
}

\author{
Keywords \\ Calcareous grasslands; Chronosequence; \\ Differentiation; $F_{\mathrm{ST}}$; Generalist; Nestedness; \\ Spatial configuration; Specialist

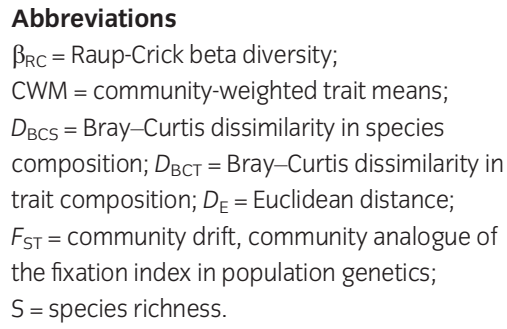

Helsen, K. (corresponding author, kenny. helsen@bio.kuleuven.be) \&

Honnay, O. (olivier.honnay@bio.kuleuven.be): Plant Conservation and Population Biology, Department of Biology, University of Leuven, Arenbergpark 31, Heverlee BE-3001, Belgium Hermy, M. (martin.hermy@ees.kuleuven.be): Division Forest, Nature and Landscape, Department Earth and Environmental Sciences, University of Leuven, Celestijnenlaan 200E, Heverlee BE-3001, Belgium

\begin{abstract}
Question: Unlike above-ground plant community assembly, the processes that govern assembly of the soil seed bank following severe habitat disturbance are poorly understood. Two hypotheses have been put forward in this context: (1) the 'ecological palimpsest hypothesis' assumes a gradual accumulation of species in the seed bank; and (2) the 'community disassembly hypothesis' assumes a gradual deterministic loss of species from the seed bank. Here, we investigated which hypothesis is applicable to the seed bank assembly of semi-natural grasslands, following forest clearance. Furthermore, we asked whether seed bank community divergence occurred at the species and at the functional trait level.
\end{abstract}

Location: Restored and ancient (old) calcareous grasslands in south Belgium.

Methods: The species composition of 106 seed bank samples from three restoration age classes were obtained through a germination experiment. Communityweighted means were calculated for 26 functional traits. We evaluated changes in species and functional composition with increasing grassland age. Differentiation in species and trait composition was compared between age groups. Finally, we tested for the occurrence of nestedness of the seed bank communities according to age.

Results: Seed bank species richness decreased with time since restoration, at the trait level reflected by the replacement of traits associated with generalist therophytes by traits typical for chamaephytes and grassland specialists. Whereas species differentiation remained relatively constant, trait differentiation decreased with time since restoration. The seed bank composition of old grasslands was a nested subset of that of young grasslands.

Conclusions: Our results suggest that the 'community disassembly hypothesis' is applicable to the community assembly of semi-natural grasslands. Directly following forest clearance, a diverse seed bank is formed, followed by a gradual net loss of species. Surprisingly, this species loss is not governed by seed persistence traits but by functional changes in the above-ground community. This disassembly process results in one deterministic end state at the trait level, but not at the species level.

\section{Introduction}

In an attempt to halt species loss and community degradation, large-scale habitat restoration projects have been set up worldwide (Rey Benayas et al. 2009). The success of these projects is largely dependent on adequate understanding of the ecological processes at play during habitat restoration. In contrast to the considerable quantity of research performed on the above-ground plant community assembly following ecological restoration, relatively little attention has been devoted to processes affecting the within and among site variation of the species diversity of 
the soil seed bank following restoration. Most research so far has mainly focused on quantifying changes in seed bank species richness and similarity between seed bank and standing vegetation composition, but often lacks ability to generate general seed bank assembly patterns (e.g. Bisteau \& Mahy 2005; Von Blanckenhagen \& Poschlod 2005; Koch et al. 2011). Yet, clear insight into seed bank assembly patterns is of considerable relevance for both restoration and conservation, since a well-developed seed bank may act as a genetic and taxonomic reservoir for the present plant community, buffering populations against environmental disturbance and stochasticity (Kalamees \& Zobel 2002; Honnay et al. 2008; Mandák et al. 2012). Furthermore, although dependent on the habitat type, seed banks can aid restoration of the above-ground community (Bossuyt \& Honnay 2008).

Two non-exclusive hypotheses can be put forward regarding changes in species composition of the seed bank following a severe disturbance event, which usually accompanies initial restoration measures. The first hypothesis states that the species richness of the seed bank will gradually increase, with viable seeds of species of each successional stage accumulating in the soil, resulting in an 'ecological palimpsest' end state composition (Davies \& Waite 1998). Following this hypothesis, the seed bank composition of early restoration sites is predicted to be a nested subset of the seed bank composition of the end state community (Davies \& Waite 1998). Some evidence for this hypothesis has been obtained during grassland succession following grazing and mowing abandonment (Davies \& Waite 1998; Falinska 1999). A second hypothesis assumes that the progression in above-ground assembly is accompanied by a belowground community disassembly of the seed bank. According to this hypothesis, the seed bank is formed immediately following a disturbance event, after which species are gradually and non-randomly lost, depending on their seed characteristics (Zavaleta et al. 2009). According to this hypothesis, the seed bank composition of the end state community is predicted to be a nested subset of the seed bank composition of early restoration sites (Royo \& Ristau 2012). Several studies focusing on changes in forest seed bank composition following a disturbance event have found partial support for this hypothesis (Van Calster et al. 2008; Plue et al. 2010; Royo \& Ristau 2012), but evidence from other vegetation types is currently lacking (Bekker et al. 2000; but see Kalamees \& Zobel 1997).

Although both the palimpsest and the disassembly hypothesis state that changes in seed bank composition are predictable, the exact species composition of the resulting seed bank community is expected to be unpredictable and heavily contingent upon the initial species composition of the seed bank, which is, in turn, determined by the present or historical above-ground species composition (Bekker et al. 2000; Rosef 2008; Van Calster et al. 2008). The effects of stochastic processes, habitat configuration, landuse legacies and priority effects can therefore be expected to result in a different seed bank composition across different restoration sites (Falinska 1999; Fagan et al. 2010; Auffret $\delta$ Cousins 2011). Divergence in seed bank species composition has indeed been observed among abiotically similar sites (Willems \& Bik 1998; Van Calster et al. 2008; Royo \& Ristau 2012).

At the functional trait level, however, above-ground community assembly has been observed to remain more or less deterministic, resulting in strong trait convergence among different restoration sites in time. This convergence is thought to be solely defined by the available niches, which are, in turn, defined by site-level abiotic and climatic conditions (Fox 1987; Fukami et al. 2005; Helsen et al. 2012). When assuming that seed bank patterns are mainly defined by the present (and former) above-ground community, changes in seed bank composition can also be expected to be deterministic at the functional trait level. This can in turn result in a strong functional signal during seed bank assembly (Meers et al. 2012). Seed bank trait composition can alternatively also be expected to be governed by functional traits that affect seed longevity, also leading to a similar suite of traits present among different restoration sites (Falinska 1999; Fagan et al. 2010; Pakeman \& Eastwood 2013). The limited research performed so far on seed bank functional trait composition has indeed observed directional changes during assembly, leading to an increase in stress-tolerant species, mean plant longevity and fruit dispersal, and a decrease in the number of therophytes/ruderal species, associated with a decrease in mean flowering duration and nutrient preference (Ellenberg $\mathrm{N}$ ) for European calcareous grassland assembly (Bossuyt et al. 2006; Fagan et al. 2010). Research in European temperate forests showed a temporal increase in mean seed longevity and a decrease in mean seed weight in the seed bank since the last disturbance (Van Calster et al. 2008).

In this study we investigated changes in the seed bank plant community of semi-natural grasslands at both the species and functional trait level, following grassland restoration on former forest stands. Grassland communities were sampled in seven separate grassland fragments over three age groups using a high number of soil samples for each location (80 point samples per hectare grassland). More specifically, we addressed the following questions:

1 Does species richness and composition of the seed bank of restored grasslands change with time since restoration, and does this result in changes in the relative proportions of generalist and specialist species? Furthermore, how is this reflected at the functional trait level? 
2 Are changes in seed bank composition deterministic at the species and functional trait level? More specifically, does differentiation among seed bank communities decrease with increasing time since restoration?

3 Can we find support for either the 'ecological palimpsest' or the 'community disassembly' hypotheses? Or more specifically, how are the different seed bank communities nested in each other with respect to time since restoration?

\section{Methods}

\section{Study area}

The study area comprises several calcareous grasslands (Festuco-Brometea) in the valley of the river Viroin, $75 \mathrm{~km}$ south of Brussels (Butaye et al. 2005). These grasslands occur on isolated stony outcrops surrounded by forests and cultivated land. Most of these grasslands became highly fragmented in the last century due to active forest plantation and shrub encroachment. Recent restoration practices have resulted in the reinstatement of ca. 100 ha of calcareous grassland between 2001 and 2007, resulting in larger grasslands consisting of grassland patches of different ages (Helsen et al. 2012). Restoration practices consisted of clearance of the tree and shrub layer, and subsequent removal of all organic material, after which spontaneous colonization of the bare soil occurred. Soil characteristics were not directly altered, nor were plant species introduced, resulting in very similar abiotic starting conditions across the different restored grasslands (André \& Vandendorpel 2004; Piqueray et al. 2011). Most restored grassland patches were adjacent to mature calcareous grassland patches, from which dispersal of species could occur (Fig. 1). Colonization of grassland species was only facilitated through the movement of sheep, with no deliberate introduction of seeds or seedlings.

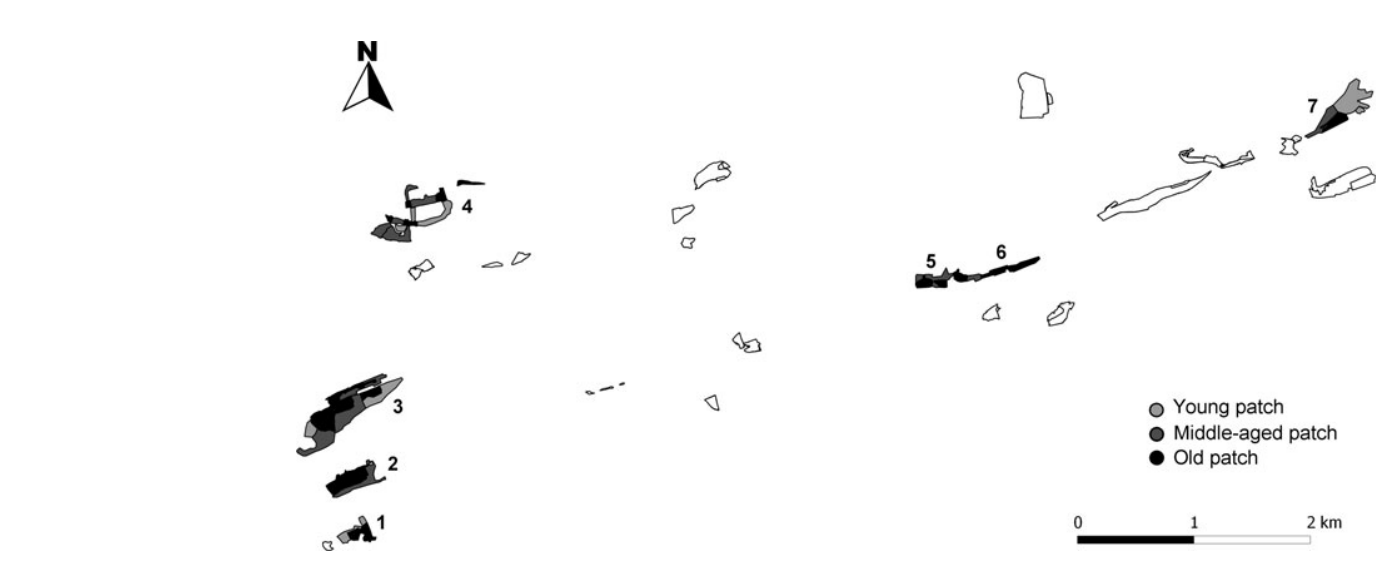

\section{Data collection}

Seed bank samples were collected from several calcareous grassland patches of different size over three age groups: young (restored between 2005 and 2007; 5-7 yr old), middle-aged (restored between 2001 and 2004; 8-11 yr old) and old (ancient calcareous grassland), during September of 2012. At each patch, two $2 \mathrm{~m} \times 2 \mathrm{~m}$ plots were randomly selected for each hectare of grassland, resulting in a total of 106 plots. These patches (and plots) were spatially clustered in seven larger calcareous grassland fragments (Fig. 1, App. S2). We collected a high number of soil samples for each location to overcome the often-observed diversity bias in seed bank studies (Plue \& Hermy 2012). At each plot, 40 random soil samples were taken with a $2 \mathrm{~cm}$ diameter soil auger, and bulked together. Due to the shallow nature of the soil, samples were taken up to the mineral bedrock $(<15 \mathrm{~cm})$. The top centimeter of each sample was removed to exclude transient seeds present on the surface. The samples were concentrated using a coarse $(4 \mathrm{~mm})$ and a fine $(0.2 \mathrm{~mm})$ sieve (Ter Heerdt et al. 1996). The concentrated samples were thinly $(<1 \mathrm{~cm}$ depth) spread out on plastic containers $(40 \mathrm{~cm} \times 45 \mathrm{~cm})$ filled with sterile potting soil. Seeds in these samples were allowed to germinate under standard conditions for $15 \mathrm{wk}$ (16 h light/ $8 \mathrm{~h}$ darkness, $20-30{ }^{\circ} \mathrm{C}$ day temperatures), followed by an 8 wk cold stratification period $\left(2{ }^{\circ} \mathrm{C}\right)$. After the cold stratification, the samples were subjected to a second germination period of $15 \mathrm{wk}$. Five control containers without seed samples were included in the experiment to test for contamination of airborne seeds or seeds present in the potting soil.

\section{Plant traits}

A total of 26 functional plant traits were selected for further analyses, based on their relevance for community

Fig. 1. Sampled grassland patches in the Viroin valley. Grassland codes: 1: Roche Trouée; 2: Fondry des Chiens; 3: Les Abannets; 4: Montagne aux Buis; 5: Roche Madoux; 6: Desous le Transoi; 7: Tienne Saumières. 
assembly, including the processes of dispersal, establishment and persistence (cf. Weiher et al. 1999; App. S1). Trait values were extracted from different sources (Fitter $\&$ Peat 1994; Lambinon et al. 1998; Klotz et al. 2002; Poschlod et al. 2003; Kleyer et al. 2008). The seed longevity index was calculated according to Bekker et al. (1998), based on seed longevity data of Thompson et al. (1997). In total, $91.7 \%$ of all trait values were available for all species. The functional traits, plant height, seed mass and seed number, were logarithmically transformed before further analysis to reduce the effect of extreme values.

The weighted average value of each trait was calculated for each plot (community-weighted trait means, CWM) according to the method of Díaz et al. (2007) with FDiversity (Casanoves et al. 2011). Prior to CWM calculation, we recoded nominal traits as dummy variables and standardized trait state values of each ordinal and ratio trait to range from zero (minimum) to one (maximum) over all species of the species pool. This guarantees equal weight for all traits during subsequent analyses. CWM values for all 26 traits were used for the construction of a species $\times$ trait matrix.

\section{Data analysis}

\section{Species and trait composition}

The species richness of the soil seed bank $(S)$ and the total germinated seed density per $\mathrm{m}^{2}$ were calculated for each plot, including all species, generalist species only and specialist species only. Specialist species were defined as species mainly confined to calcareous grasslands in Belgium (Lambinon et al. 1998; Van Landuyt et al. 2006). All remaining species that occurred over a larger range of habitat types in Belgium were defined as generalist species. Each plot was assigned to one of the three grassland patch age classes (young, middle-aged and old). Seed bank species richness and seed density were compared between the different age classes using linear mixed models (LMM, SPSS Statistics 20.0; SPSS, Chicago, IL, US). Since plots were clustered in seven grasslands, grassland identity was included as a random factor in these models. Semi-partial $R_{\text {beta }}^{2}$ coefficients were calculated using the method of Edwards et al. (2008). Pairwise comparisons of the three age classes were corrected for increased type-I error by applying Bonferroni corrections. Species richness and seed density of specialist species and generalist species was divided by the total species richness/seed density of each plot, respectively, to obtain the proportional richness/seed density before analysis with LMM. All three measures of seed density were square root transformed to obtain a normal distribution before analysis.

Significant differences in species composition between age classes were inferred using the multi-response permutation procedure (MRPP) based on Bray-Curtis distances in species composition among plots, calculated on the square root transformed plot $\times$ species matrix in PC-ORD 6.0 (MjM Software Design, Gleneden Beach, OR, US). MRPP is a nonparametric permutation method used for testing multivariate differences among predefined groups (McCune \& Grace 2002). Pairwise comparison of differences in species composition between age classes was also performed with MRPP, with application of Bonferroni correction of the resulting $P$-values. Since the number of plots was not equal among grasslands, we were not able to include grassland identity as a nested factor in the design, to correct for the dependent nature of the data.

Significant differences in trait composition of seed bank communities between age classes were tested using SumF in PC-ORD 6.0. This method calculates an $F$ statistic for each functional trait (CWM) independently, based on the difference between age classes. To test for significant differences in overall trait composition of the seed bank between age classes, these univariate $F$ statistics were summed and compared to the distribution of $F$ statistics based on 9999 randomizations of the data under the null hypothesis of no difference. Pairwise comparisons of age classes were also included in the SumF analysis, with application of Bonferroni correction of the resulting $P$-values. We were not able to include grassland identity as a nested factor in the design because the number of plots was not equal among grasslands. To correct for the dependent nature of our data we also performed independent LMM on the CWMs for each trait, with grassland patch age as a fixed factor and grassland identity as a random factor. Significance levels were inferred using a bootstrapping procedure of 9999 bootstraps (SPSS Statistics; SPSS). We used the false discovery rate (FDR) approach of Benjamini \& Hochberg (1995) to control the level of type-I error. The results of these LMMs were compared to those of the SumF analysis to infer the effects of data clustering on our results.

\section{Species and trait differentiation}

Pairwise differentiation in species composition between seed bank plots was characterized using three differentiation measures based on the square root transformed plot $\times$ species matrix: the Bray-Curtis dissimilarity $\left(D_{\mathrm{BCS}}\right)$, Raup-Crick beta diversity $\left(\beta_{\mathrm{RC}}\right)$ and a community analogue of the fixation index in population genetics $\left(F_{\mathrm{ST}}\right)$. $\beta_{\mathrm{RC}}$ is a presence-absence-based probabilistic measure of differentiation that is independent of species richness (Raup \& Crick 1979). $D_{\mathrm{BCS}}$ and $F_{\mathrm{ST}}$ are both based on abundance data, with $F_{\mathrm{ST}}$ being the difference in relative cover of species between plots, calculated as defined in 
Vellend et al. (2004; Baeten et al. 2010). Since $F_{\mathrm{ST}}$ is known to be strongly affected by dominant species (alleles; Meirmans \& Hedrick 2011), $F_{\text {ST }}$ was calculated leaving out the five most frequent species (occurring in $>43 \%$ of all plots). Pairwise differentiation in trait (CWM) composition between seed bank plots was also characterized, using two differentiation measures: the Euclidean distance $\left(D_{\mathrm{E}}\right)$ and the Bray-Curtis dissimilarity $\left(D_{\mathrm{BCT}}\right)$.

Species and trait differentiation among plots were compared between age classes using ANOVA on pairwise species and trait differentiation values. Since plots are clustered within seven grasslands, mean pairwise species and trait differentiations were first pooled for each combination of grasslands for this analysis, resulting in a grassland $\times$ grassland differentiation matrix. Because of the dependency of pairwise data, a bootstrapping procedure of 9999 bootstraps was applied for calculation of the test statistics and $95 \%$ confidence intervals (SPSS). To control the level of type-I error, the $95 \%$ confidence intervals were adapted using the false discovery rate (FDR) approach of Benjamini \& Hochberg (1995).

\section{Nestedness}

Finally, we performed a nestedness analysis using the 'nestedness metric based on overlap and decreasing fill' (NODF) to test for nested seed bank patterns within the maximally packed plot $\times$ species matrix. For this analysis, we used both a presence-absence and an abundance-based NODF null model, randomized with fixed total abundance. Significance was tested using 1000 randomizations (Almeida-Neto \& Ulrich 2010). If significant nestedness was observed, we tested whether this pattern is related to grassland patch age. This was accomplished by comparing the mean rank-order of the plots in the maximally packed matrix between different age classes using a LMM, analogous to those performed on the species diversity measures (SPSS).

\section{Results}

\section{Species and trait composition}

A total of 4266 seeds of 140 different species germinated (App. S2). Two species (Juncus tenuis and Salix caprea) were observed in the control containers, indicating possible contamination of the sterile soil. These species were removed from the species list.

Total species richness was significantly higher for the seed bank of young grassland patches compared to old grassland patches (Table 1), a trend also visible in the total seed density, although not significant $(F=2.44$, $P=0.092$; Table 1). This same pattern was even more pronounced for the proportional generalist species richness and seed density, with a gradual decrease through time over the three age classes (Fig. 2a). In contrast, the number of specialist species gradually increased through time, resulting in the highest occurrence in the seed bank of old grassland patches, both with respect to the number of seeds and the number of species (Table 1, Fig. 2a).

The MRPP analysis shows the presence of a significant difference is species composition between seed bank plots of different grassland age (overall $T=-16.41, P<0.001$; contrast old - m.a. $T=-14.48, P<0.001$; contrast m.a. young $T=-2.23, \quad P=0.025$; contrast old - young $T=-16.84, P<0.001)$. The SumF analysis, on the other hand, showed that a significant difference in overall trait composition occurs between seed bank plots from different age classes (overall $F=218.96, P<0.001$; contrast old m.a. $F=255.94, \quad P<0.001$; contrast m.a. $\quad$ young $F=63.97, P=0.038$; contrast old - young $F=420.49$, $P<0.001)$. Bootstrapping LMM showed that these overall differences could be translated into clear shifts in independent functional traits between age groups (App. S3). The seed bank composition of old grassland patches was characterized by a lower proportion of phanerophytes and therophytes compared to middle-aged grassland patches, resulting in a lower mean value for soil nutrient preference,

Table 1. Parameter estimates of the model relating seed bank diversity indices to grassland age using LMM. Test statistic $(F)$ and semi-partial $R^{2}$ beta given for age $(N=106)$. Beta coefficients (means) are given for each age group. Pairwise comparisons (contrasts) were generated after Bonferroni correction.

\begin{tabular}{|c|c|c|c|c|c|c|c|c|}
\hline & $F$ & $R_{\text {beta }}^{2}$ & Beta & Beta & Beta & Contrast & Contrast & Contrast \\
\hline & & & Old & m.a. & Young & Old-m.a. & m.a.-Young & old-Young \\
\hline$S$ & $3.2^{\star}$ & 0.034 & 10.33 & 11.62 & 12.81 & -1.30 & -1.19 & $-2.48^{\star}$ \\
\hline S spec. & $34.0 * * *$ & 0.249 & 0.56 & 0.34 & 0.21 & $0.23^{\star \star \star}$ & $0.13^{\star \star}$ & $0.36^{\star * \star}$ \\
\hline S gen. & $32.6^{\star \star *}$ & 0.241 & 0.44 & 0.66 & 0.79 & $-0.22^{\star \star \star}$ & $-0.14^{\star \star}$ & $-0.35^{\star \star \star}$ \\
\hline$\sqrt{ }$ (Dens.) & 2.4 & 0.023 & 5.31 & 6.31 & 5.64 & -1.00 & 0.68 & -0.32 \\
\hline$\sqrt{ }$ (Dens. spec.) & $25.4^{\star \star \star \star}$ & 0.198 & 0.74 & 0.54 & 0.40 & $0.21 * \star \star$ & $0.14^{*}$ & $0.35^{\star * \star}$ \\
\hline$\sqrt{ }$ (Dens. gen.) & $17.6^{* \star *}$ & 0.146 & 0.63 & 0.79 & 0.90 & $-0.16^{\star \star \star}$ & $-0.11^{*}$ & $-0.27^{\star \star \star}$ \\
\hline Rank & $3.2^{\star}$ & 0.032 & 12.67 & 11.37 & 10.21 & 1.30 & 1.16 & $2.46^{\star}$ \\
\hline
\end{tabular}

S, species richness; Dens., seed density; m.a., middle-aged (age group); Rank, rank-order of the plots in the maximally packed matrix; spec., specialist; gen., generalist. Significance: $* 0.05 \geq P>0.01 ; * 0.01 \geq P>0.001 ; * * * 0.001 \geq P$. 

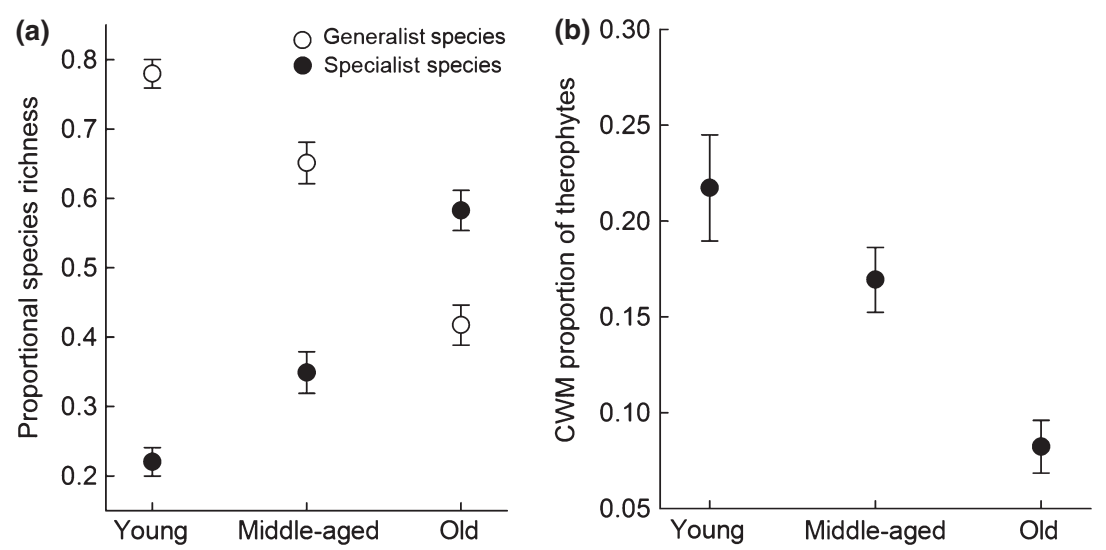

Fig. 2. (a) Changes in the proportional species richness with increasing time since restoration (grassland patch age). (b) Changes in the communityweighted mean proportion (CWM) of therophytes with increasing time since restoration. Means and SE bars are presented for each age class.

seed shape, seed number, seed longevity and the proportion of autogamous species, and a higher mean value for life span and age of first flowering, all of which are plant trait syndromes typically associated with therophytes (Fig. 2b). We also observed a significantly higher proportion of chamaephytes in old seed bank communities. The seed bank of old grassland patches was furthermore characterized by a higher mean value of autochory and epizoochory and a lower mean value for leaf size, clonality (reproductive type) and hemerochory (dispersal by human action). Several of these changes in trait composition from middle-aged toward old seed bank communities were also visible in the transition from young toward old seed bank communities (App. S3). However, we also observed several independent trait differences between the seed bank of young and middle-aged/old grassland patches. The seed bank of young grassland patches was characterized by a higher mean value for dysochory (dispersal by scatter-hoarding animals) and seed length and a lower proportion of rosette species compared to both middle-aged and old grassland patches. Compared to old grassland patches, the seed bank of young grasslands patches was characterized by a lower mean value for light preference and proportion of insect-pollinated species and a higher proportion of selfing species. Finally, mean seed mass was observed to increase from young toward middle-aged seed bank communities, followed by a decrease from middle-aged to old seed bank communities.

\section{Species and trait differentiation}

Species differentiation among grasslands was significantly higher for middle-aged seed bank communities compared to old seed bank communities based on $F_{\text {ST }}$ (Table 2). No significant differences in species differentiation among age groups were observed for $D_{\mathrm{BCS}}$ and $\beta_{\mathrm{RC}}$. Trait differentiation among grasslands showed a significantly lower differentiation for old seed bank communities compared to middle-aged seed bank communities, based on $D_{\mathrm{E}}$ and $D_{\mathrm{BCT}}$ (Table 2). The average geographic distance separating grasslands, however, was not significantly different between the three age classes (Table 2).

Table 2. Parameter estimates of performed pairwise comparisons after bootstrapping ANOVA on pairwise differentiation and geographic distance between different grassland patch age classes. All tests are based on 9999 bootstraps.

\begin{tabular}{|c|c|c|c|c|c|c|}
\hline & \multicolumn{2}{|c|}{ Contrast Old-m.a. } & \multicolumn{2}{|c|}{ Contrast m.a.-Young } & \multicolumn{2}{|c|}{ Contrast Old-Young } \\
\hline & Mean diff. & $\mathrm{Cl}$ & Mean diff. & $\mathrm{Cl}$ & Mean diff. & $\mathrm{Cl}$ \\
\hline Species: $D_{\mathrm{BCS}}$ & 0.015 & -0.056 to 0.088 & 0.017 & -0.053 to 0.079 & 0.032 & -0.053 to 0.119 \\
\hline Species: $\beta_{\mathrm{RC}}$ & -0.062 & -0.166 to 0.051 & 0.040 & -0.134 to 0.185 & -0.022 & -0.191 to 0.119 \\
\hline Species: $F_{\mathrm{ST}}$ & $-0.060^{\star}$ & -0.091 to -0.030 & 0.042 & -0.005 to 0.093 & -0.018 & -0.060 to 0.031 \\
\hline Traits: $D_{\mathrm{E}}$ & $-0.167^{\star}$ & -0.255 to -0.078 & 0.084 & -0.074 to 0.251 & -0.083 & -0.233 to 0.068 \\
\hline Traits: $D_{\mathrm{BCT}}$ & $-0.026^{\star}$ & -0.043 to -0.011 & 0.014 & -0.014 to 0.042 & -0.012 & -0.038 to 0.014 \\
\hline Geographic Distance & -122.9 & -2401.7 to 2124.5 & -712.6 & -4958.5 to 3453.8 & -835.5 & -5025.6 to 3244.8 \\
\hline
\end{tabular}

$\mathrm{Cl}$, 95\% confidence intervals following FDR correction; Mean diff., mean difference; m.a., middle-aged (age group). Note that significance is not inferred from $P$-values but from the $\mathrm{Cls}$, * only indicates significance, not the size of the $P$-value. 


\section{Nestedness}

Seed bank composition showed a significantly nested pattern for both the presence-absence $($ NODF $=18.9$, $Z=-21.7, P<0.001)$ and abundance-based (WNODF $=$ 8.5, $Z=-16.3, P<0.001)$ analysis. This nested pattern was significantly affected by grassland age, with a significant difference between young and old grassland patches (Table 1). Although not significant, middle-aged grassland patches showed a mean rank intermediate to that of young and old grassland patches, suggesting a gradual increase in rank number with increasing time since restoration. This indicates that the species composition of the seed bank of old grassland patches is, at least partly, a nested subset of the species composition of the seed bank of restored grassland patches.

\section{Discussion}

\section{Species and trait composition}

Species richness in the soil seed bank is often observed to decrease during secondary succession, usually accompanied by a decline in seed density (e.g. Davies \& Waite 1998; Falinska 1999; Bekker et al. 2000). Our study confirms this pattern during calcareous grassland community assembly following restoration. Although the total number of species per soil sample decreased through time, we observed that the proportional number of specialist species and its number of seeds gradually increased. This suggests a significantly higher loss of generalist species and seeds from the soil seed bank than a gain of specialist species. This pattern can be expected if specialist species are characterized by increased seed longevity compared to generalist species (Royo \& Ristau 2012). This, however, is not the case in our study system, where generalists from restored calcareous grasslands mainly consist of annual therophyte species (Bisteau \& Mahy 2005; Fagan et al. 2010; Helsen et al. 2013), showing a significantly higher seed longevity than specialist species. The observed pattern can alternatively be explained through changes in seed input from the above-ground vegetation (Bekker et al. 2000; Bisteau \& Mahy 2005). Previous research on these grasslands indeed established that generalist species are gradually replaced by specialist species in the aboveground community, with increasing time since restoration (Helsen et al. 2013). This indicates that the seed bank of generalist species is gradually depleted through predation and mortality. For specialist species, on the other hand, these processes are mitigated by the influx of new seeds from the above-ground vegetation (Falinska 1999; Bekker et al. 2000; Rosef 2008). Not surprisingly, this shift in seed bank composition from a generalist- towards a specialist-dominated community was accompanied by a significant directional change in the species composition of the soil seed bank communities, as observed in the MRPP analysis.

More interestingly, this species composition shift is accompanied by strong changes in its functional trait composition. The observed functional seed bank shift consisted of a partial replacement of therophytes and phanerophytes by chamaephytes, consistent with the replacement of generalist by specialist species (Helsen et al. 2013). This is partly consistent with the study of Fagan et al. (2010), reporting the replacement of therophytes with hemicryptophytes in the seed bank, following initial restoration of calcareous grasslands in southern England. The changes in life-form composition, observed in our study, can help explain the directional changes in trait composition. The loss of therophytes, for example, can explain changes in the mean seed size, number and longevity, nutrient preference and life span of the seed bank community (Fagan et al. 2010; Meers et al. 2012). Again, most of these trait changes are likely driven by the progressive changes in the seed influx composition from the above-ground vegetation (cf. Klimkowska et al. 2010). When focusing specifically on seed traits, however, we observe patterns opposite to those predicted from theory and in other observational studies (Falinska 1999; Van Calster et al. 2008; Royo \& Ristau 2012). Indeed, following the 'community disassembly' framework, progress in assembly at the soil seed bank level is expected to be, at least partly, governed by the predictable loss of species producing only a small number of seeds and of species with large seeds or low seed longevity, all traits expected to reduce the survival of a species in the seed bank (Thompson et al. 1993; Bekker et al. 1998). Our results indicate, however, that the loss of therophytes from the above-ground vegetation has a stronger functional signal than the predictable traitgoverned loss of seeds from the seed bank. This is in accordance with a hayfield succession study in the Netherlands (Bekker et al. 2000), where a reduction in the mean seed longevity of the seed bank with the progress of succession was observed. Bossuyt et al. (2006) also observed the absence of a predictable loss of species from the seed bank based on seed bank longevity with progress during succession from calcareous grassland toward scrub in our study area. The seed dispersal capacity spectrum was also observed to significantly respond to time since restoration, with the replacement of hemerochore and dysochore species by autochore and epizoochore species. This possibly reflects the later arrival of the latter species in the community because of reduced dispersal capacities (cf. Helsen et al. 2013). Interestingly, Van Calster et al. (2008) observed no effects of dispersal ability on seed bank assembly in temperate forests. 


\section{Species and trait differentiation}

Looking at species differentiation, only $F_{\mathrm{ST}}$ was observed to significantly differ among age groups. $F_{\mathrm{ST}}$ was higher for seed bank plots of middle-aged grassland patches compared to those of old grassland patches. This indicates lower community drift (divergence in local abundances) for old grasslands, suggesting species abundance convergence in the seed bank of old grassland patches (Vellend et al. 2004; Baeten et al. 2010). Nevertheless, we can conclude that no clear convergence in species composition occurs with increasing time since restoration. Other studies have also observed the absence of convergence, and even increasing divergence, of the seed bank species composition with progression in time in temperate forests (Van Calster et al. 2008; Royo \& Ristau 2012) and calcareous grasslands (Willems \& Bik 1998).

At the trait level, however, a significant decrease in differentiation between middle-aged and old seed bank communities occurred. The same trend, although not significant, is present for young seed bank communities, showing higher differentiation than old seed bank communities. Since young grassland patches were only available in four of the seven sampled grasslands, only a small number of pairwise grassland $\times$ grassland differentiation values was obtained for young grassland patches, possibly explaining why no significant effects were observed. For this reason we believe that, at least to a certain extent, predictable changes in trait composition occur with elapse in time since restoration, resulting in trait convergence over time. These results are in accordance with patterns observed in the above-ground vegetation of our study area, where trait convergence was observed, whereas at the species level, community composition remained differentiated (Helsen et al. 2012).

\section{Community disassembly vs ecological palimpsest (nestedness)}

Our results support the 'community disassembly' hypothesis (Zavaleta et al. 2009) rather than the 'ecological palimpsest' hypothesis (Davies \& Waite 1998). To our knowledge, this is the first study providing proof for this hypothesis during semi-natural grassland assembly. This implies that the seed bank species composition of old patches forms a nested subset of the seed bank species composition of young patches. This suggests that after initial restoration, the open soil acts as a seed recipient, quickly building up a large seed bank within the first years after restoration, followed by a stage of gradual net loss of species with time (Fagan et al. 2010). Surprisingly, this species loss is not governed by seed traits promoting seed survival, as observed in forest studies (Van Calster et al.
2008; Plue et al. 2010; Royo \& Ristau 2012), but rather by changes in the above-ground vegetation (Falinska 1999; Bekker et al. 2000; Rosef 2008). This leads to the replenishment of seeds of specialist grassland species, but a depletion of the diverse therophyte community that dominates the seed bank of young calcareous grasslands (cf. Bekker et al. 2000; Bisteau \& Mahy 2005; Rosef 2008; Fagan et al. 2010). This results in a contra-intuitive decrease in mean seed bank longevity with increasing time since restoration.

Surprisingly, this disassembly process does not result in a decrease in species differentiation among seed bank plots through time, suggesting that the 'nested subset' of seed bank species present on old grassland patches is not necessarily the same at each site (Plue et al. 2010). This is further confirmed by the occurrence of a significant effect of distance on the seed bank differentiation among old grasslands, indicating differential species compositions between geographically distant seed bank plots. A similar pattern of nested species composition of old sites, but higher differentiation among old sites, has been observed for temperate hardwood forests in the USA (Royo \& Ristau 2012). The authors of this study hypothesize that this increased differentiation is caused by the occurrence of several stochastic factors, partly undermining deterministic assembly patterns. More specifically, these stochastic factors are identified as being: (1) inter-site variation in establishment and extinctions of species from seeds among locations; (2) Long-distance colonization events; and (3) in situ colonization of seeds from local reproduction events (Royo \& Ristau 2012). The same patterns likely apply to our study system. At the functional trait level, however, this 'end state' composition seems to be more deterministic, leading to a decrease in differentiation among seed bank plots in trait composition and no effects of spatial configuration on the seed bank trait differentiation.

\section{Acknowledgements}

This paper was written when K.H. held a grant from the Flemish Fund for Scientific Research (FWO). Thanks to Dries Adriaens, Louis-Marie Delescaille and Léon Woué for providing information about the study area; to Stijn Cornelis, Martine Leijssen, Sofie Meeus, Roel Schrauwen, Reinhardt Strubbe and Kasper Van Acker for assistance in the field or during analysis; and to Jeroen Tirry and Eric Van Beek for assistance in the greenhouse.

\section{References}

Almeida-Neto, M. \& Ulrich, W. 2010. A straightforward computational approach for quantifying nestedness using abundance data. Environmental Modelling $\theta$ Software 26: 173-178. 
André, B. \& Vandendorpel, A. 2004. Le projet LIFE Nature de restauration et de gestion des milieux calcaires en Lesse et Lomme (PROJET LIFE 2000 NATURE/B/7168): une tradition pastorale séculaire en dernier recours. Parcs Réserves 59: $22-37$.

Auffret, A.G. \& Cousins, S.A.O. 2011. Past and present management influences the seed bank and seed rain in a rural landscape mosaic. Journal of Applied Ecology 48: 1278-1285.

Baeten, L., Hermy, M., Van Daele, S. \& Verheyen, K. 2010. Unexpected understorey community development after 30 years in ancient and post-agricultural forests. Journal of Ecology 98: 1447-1453.

Bekker, R.M., Bakker, J.P., Grandin, U., Kalamees, R., Milberg, P., Poschlod, P., Thompson, K. \& Willems, J.H. 1998. Seed size, shape and vertical distribution in the soil: indicators of seed longevity. Functional Ecology 12: 834-842.

Bekker, R.M., Verweij, G.L., Bakker, J.P. \& Fresco, L.F.M. 2000. Soil seed bank dynamics in hayfield succession. Journal of Ecology 88: 594-607.

Benjamini, Y. \& Hochberg, Y. 1995. Controlling the false discovery rate: a practical and powerful approach to multiple testing. Journal of the Royal Statistical Society B 57: 289-300.

Bisteau, E. \& Mahy, G. 2005. Vegetation and seed bank in a calcareous grassland restored from a Pinus forest. Applied Vegetation Science 8: 167-174.

Bossuyt, B. \& Honnay, O. 2008. Can the seed bank be used for ecological restoration? An overview of seed bank characteristics in European communities. Journal of Vegetation Science 19: 875-884.

Bossuyt, B., Butaye, J. \& Honnay, O. 2006. Seed bank composition of open and overgrown calcareous grassland soils - a case study from Southern Belgium. Journal of Environmental Management 79: 364-371.

Butaye, J., Honnay, O., Adriaens, D., Delescaille, L.M. \& Hermy, M. 2005. Phytosociology and phytogeography of the calcareous grasslands on Devonian limestone in southwest Belgium. Belgian Journal of Botany 138: 24-38.

Casanoves, F., Pla, L., Di Rienzo, J.A. \& Díaz, S. 2011 . FDiversity: a software package for the integrated analysis of functional diversity. Methods in Ecology e Evolution 2: 233-237.

Davies, A. \& Waite, S. 1998. The persistence of calcareous grassland species in the soil seed bank under developing and established scrub. Plant Ecology 136: 27-39.

Díaz, S., Lavorel, S., de Bello, F., Quétier, F., Grigulis, K. \& Robson, M.T. 2007. Incorporating plant functional diversity effects in ecosystem service assessments. Proceedings of the National Academy of Sciences of the United States of America 104: 20684-20689.

Edwards, L.J., Muller, K.E., Wolfinger, R.D., Qaqish, B.F. \& Schabenberger, O. 2008. An $R^{2}$ statistic for fixed effects in the linear mixed model. Statistics in Medicine 27: 61376157.

Fagan, K.C., Pywell, R.F., Bullock, J.M. \& Marrs, R.H. 2010. The seed banks of English lowland calcareous grasslands along a restoration chronosequence. Plant Ecology 208: 199-211.
Falinska, K. 1999. Seed bank dynamics in abandoned meadows during a 20-year period in the Bialowieza National Park. Journal of Ecology 87: 461-475.

Fitter, A.H. \& Peat, H.J. 1994. The ecological flora database. Journal of Ecology 82: 415-425.

Fox, B.J. 1987. Species assembly and the evolution of community structure. Evolutionary Ecology 1: 201-213.

Fukami, T., Bezemer, M.T., Mortimer, S.R. \& Putten, W.H. 2005. Species divergence and trait convergence in experimental plant community assembly. Ecology Letters 8: 1283-1290.

Helsen, K., Hermy, M. \& Honnay, O. 2012. Trait but not species convergence during plant community assembly in restored semi-natural grasslands. Oikos 121: 2121-2130.

Helsen, K., Hermy, M. \& Honnay, O. 2013. Spatial isolation slows down directional plant functional group assembly in restored semi-natural grasslands. Journal of Applied Ecology 50: 404-413.

Honnay, O., Bossuyt, B., Jacquemyn, H., Shimono, A. \& Uchiyama, K. 2008. Can a seed bank maintain the genetic variation in the above-ground plant population? Oikos 117: 1-5.

Kalamees, R. \& Zobel, M. 1997. The seed bank in an Estonian calcareous grassland: comparison of different successional stages. Folia Geobotanica 31: 1-14.

Kalamees, R. \& Zobel, M. 2002. The role of the seed bank in gap regeneration in a calcareous grassland community. Ecology 83: 1017-1025.

Kleyer, M., Bekker, R.M., Knevel, I.C., Bakker, J.P., Thompson, K., Sonnenschein, M., Poschlod, P., van Groenendael, J.M., Klimeš, L., (... \& \& Peco, B. 2008. The LEDA Traitbase: a database of life-history traits of the Northwest European flora. Journal of Ecology 96: 1266-1274.

Klimkowska, A., Bekker, R.M., Diggelen, R. \& Kotowski, W. 2010. Species trait shifts in vegetation and soil seed bank during fen degradation. Plant Ecology 206: 59-82.

Klotz, S., Kühn, I. \& Durka, W. 2002. BIOLFLOR - Eine Datenbank zu biologisch-ökologischen Merkmalen der Gefäßpflanzen in Deutschland. Schriftenreihe für Vegetationskunde, 38. Bundesamt für Naturschutz, Bonn, DE.

Koch, M.A., Scheriau, C., Schupfner, M. \& Bernhardt, K.-G. 2011. Long-term monitoring of the restoration and development of limestone grasslands in north western Germany: vegetation screening and soil seed bank analysis. Flora 206: $52-65$.

Lambinon, J., De Langhe, J., Delvosalle, L. \& Duvigneaud, J. 1998. Flora van België, het Groothertogdom Luxemburg, NoordFrankrijk en de aangrenzende gebieden (Pteridofyten en Spermatofyten). Nationale plantentuin van België, Meise, BE.

Mandák, B., Zákravský, P., Mahelka, V. \& Plačková, I. 2012. Can soil seed banks serve as genetic memory? A study of three species with contrasting life history strategies. PLoS One 7: e49471.

McCune, B. \& Grace, J.B. 2002. Analysis of ecological communities. MjM Software, Gleneden Beach, OR, US. 
Meers, T.L., Enright, N.J., Bell, T.L. \& Kasel, S. 2012. Deforestation strongly affects soil seed banks in eucalypt forests: generalisations in functional traits and implications for restoration. Forest Ecology and Management 266: 94-107.

Meirmans, P. \& Hedrick, P. 2011. Assessing population structure: $\mathrm{F}_{\mathrm{ST}}$ and related measures. Molecular Ecology Resources 11: 518.

Pakeman, R.J. \& Eastwood, A. 2013. Shifts in functional traits and functional diversity between vegetation and seed bank. Journal of Vegetation Science 24: 865-876.

Piqueray, J., Bottin, G., Delescaille, L., Bisteau, E., Colinet, G. $\delta$ Mahy, G. 201 1. Rapid restoration of a species-rich ecosystem assessed from soil and vegetation indicators: the case of calcareous grasslands restored from forest stands. Ecological Indicators 11: 724-733.

Plue, J. \& Hermy, M. 2012. Consistent seed bank spatial structure across semi-natural habitats determines plot sampling. Journal of Vegetation Science 23: 505-516.

Plue, J., Van Gils, B., Peppler-Lisbach, C., De Schrijver, A., Verheyen, K. \& Hermy, M. 2010. Seed-bank convergence under different tree species during forest development. Perspectives in Plant Ecology, Evolution and Systematics 12: 211-218.

Poschlod, P., Kleyer, M., Jackel, A., Dannemann, A. \& Tackenberg, O. 2003. BIOPOP - A database of plant traits and internet application for nature conservation. Folia Geobotanica 38: 263-271.

Raup, D.M. \& Crick, R.E. 1979. Measurement of faunal similarity in paleontology. Journal of Paleontology 53: 1213-1227.

Rey Benayas, J.M., Newton, A.C., Diaz, A. \& Bullock, J.M. 2009. Enhancement of biodiversity and ecosystem services by ecological restoration: a meta-analysis. Science 325: 1121-1124.

Rosef, L. 2008. Germinable soil seed banks in abandoned grasslands in central and western Norway and their significance for restoration. Applied Vegetation Science 1 1: 223-230.

Royo, A.A. \& Ristau, T.E. 2012. Stochastic and deterministic processes regulate spatio-temporal variation in seed bank diversity. Journal of Vegetation Science 24: 724-734.

Ter Heerdt, G.N.J., Verweij, G.L., Bekker, R.M. \& Bakker, J.P. 1996. An improved method for seed-bank analysis: seedling emergence after removing the soil by sieving. Functional Ecology 10: 144-151.

Thompson, K., Band, S.R. \& Hodgson, J.G. 1993. Seed size and shape predict persistence in soil. Functional Ecology 7: 236241.
Thompson, K., Bakker, J.P. \& Bekker, R.M. 1997. The soil seed banks of north-west Europe: methodology, density and longevity. Cambridge University Press, Cambridge, UK.

Van Calster, H., Chevalier, R., van Wyngene, B., Archaux, F., Verheyen, K. \& Hermy, M. 2008. Long-term seed bank dynamics in a temperate forest under conversion from coppice-with-standards to high forest management. Applied Vegetation Science 1 1: 251-260.

Van Landuyt, W., Hoste, I., Vanhecke, L., Van den Bremt, P., Vercruysse, W. \& De Beer, D. 2006. Atlas van de Flora van Vlaanderen en het Brussels Gewest. Instituut voor natuur- en bosonderzoek, Nationale Plantentuin van België \& Flo.Wer, Brussel, BE.

Vellend, M. 2004. Parallel effects of land-use history on species diversity and genetic diversity of forest herbs. Ecology 85: 3043-3055.

Von Blanckenhagen, B. \& Poschlod, P. 2005. Restoration of calcareous grasslands: the role of the soil seed bank and seed dispersal for recolonisation processes. Biotechnology, Agronomy, Society and Environment 9: 143-149.

Weiher, E., Werf, A., Thompson, K., Roderick, M., Garnier, E. \& Eriksson, O. 1999. Challenging Theophrastus: a common core list of plant traits for functional ecology. Journal of Vegetation Science 10: 609-620.

Willems, J.H. \& Bik, L.P.M. 1998. Restoration of high species density in calcareous grassland: the role of seed rain and soil seed bank. Applied Vegetation Science 1: 91-100.

Zavaleta, E., Pasari, J., Moore, J., Hernández, D., Suttle, K.B. \& Wilmers, C.C. 2009. Ecosystem responses to community disassembly. Annals of the New York Academy of Sciences 1162: 311-333.

\section{Supporting Information}

Additional Supporting Information may be found in the online version of this article:

Appendix S1. Overview of the selected traits. Appendix S2. Overview of sampled grasslands. Appendix S3. Results of SumF analysis. 


\section{Graphical Abstract}

The contents of this page will be used as part of the graphical abstract of html only. It will not be published as part of main.

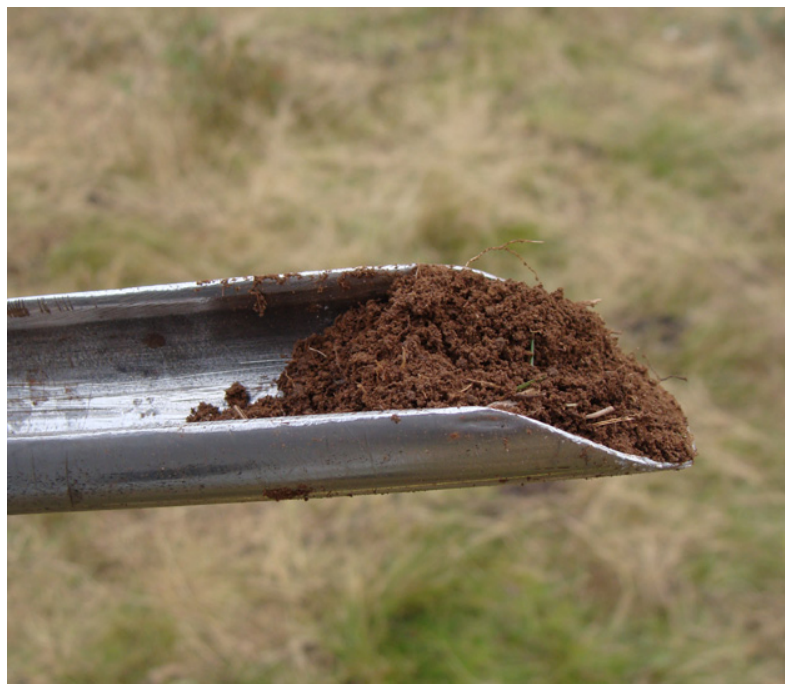

We show that during calcareous grassland assembly, a diverse seed bank is formed directly following forest clearance, followed by a gradual loss of species. This species loss is not governed by seed persistence traits but by functional changes in the above-ground community, resulting in one deterministic end state at the trait level, but not at the species level. 